\title{
Management Problems of Trans-Frontier Yellow Fever Cases in Burkina Faso 2010
}

\author{
Seydou Yaro ${ }^{1}$, Aline R. Ouoba ${ }^{1}$, Alidou Zango ${ }^{1}$, Jérémi Rouamba ${ }^{1}$, Aly Drabo $^{1}$, Soumeya Ouangraoua ${ }^{1}$, \\ Fati Samandoulougou-Kirakoya ${ }^{3}$, Jean Macq ${ }^{2}$, Annie Robert ${ }^{3}$, Jean Bosco Ouedraogo ${ }^{1}$ \\ ${ }^{1}$ Centre Muraz, Bobo-Dioulasso, Burkina Faso; ${ }^{2}$ Institut de Recherche Santé et Societé (IRSS), Faculté de Santé Publique (FSP), \\ Université Catholique de Louvain (UCL), Louvain, Belgique; ${ }^{3}$ Pôle Epidémiologie et Biostatistique, Institut de Recherche \\ Expérimentale et Clinique (IREC), Faculté de Santé Publique (FSP), Université Catholique de Louvain (UCL), Louvain, Belgique. \\ Email: yaro_seydou@yahoo.com
}

Received November $18^{\text {th }}, 2012$; revised December $18^{\text {th }}, 2012$; accepted January $19^{\text {th }}, 2013$

Copyright (C) 2013 Seydou Yaro et al. This is an open access article distributed under the Creative Commons Attribution License, which permits unrestricted use, distribution, and reproduction in any medium, provided the original work is properly cited.

\begin{abstract}
This last decade, Burkina Faso has been confronted with yellow fever confirmed cases, mainly from Western part of the country. In 2010, National Reference laboratory of yellow fever received 970 sera of suspected cases from the 65 Health Districts of the country. We found 11 positive results by ELISA test researching specific IgM against yellow fever. An aliquot of these eleven positive sera were sent to Dakar for confirmation by sero neutralization and RT-PCR. Eight have been confirmed by regional laboratory of Pasteur Institute of Dakar and three were classified as doubtful. Confirmed cases were manly notified by Sindou (4/8) and Mangodara (3/8) Health Districts and the last one came from Nongr-masson health District situated in the central part of the country. Three out of the four confirmed cases in Sindou Health District were resident from neighboring village in Ivory Cost. Conformed cases coming from neighboring villages of Ivory Cost were difficult to manage because of the relative lack of coordination between the two health centers responsible in two different countries. The three cases were not notified to Ivory Cost Health authorities and, in addition, they didn't benefit from the Burkina Faso response plan. The goal of this work is to present results from National Reference yellow fever laboratory in 2010 in Burkina Faso and stressing trans-frontier cases management problems in order to suggest a multinational mechanism of response to fight against this disease more effectively.
\end{abstract}

Keywords: Yellow Fever; Surveillance; Reference Laboratory; Trans-Frontier; Burkina Faso

\section{Introduction}

Yellow fever remains a public health problem in Africa, particularly in Western Africa area and also in Central and South America [1,2]. In America, countries like Brazil, Bolivia, Colombia, Argentina, Peru, Paraguay recently announced confirmed cases of yellow fever between 2008 and 2009 [3]. During these last decades, several countries of Africa knew epidemics of yellow fever [2]. Ivory Cost from 2001 to 2007 [4], Burkina Faso from 2003 to 2009 [5], Sierra Leone, Liberia, Guinea, Central African Republic, Chad, in 2008 [3] Senegal in 2010 [6]. Countries in Southern Africa such as Uganda [7], Democratic Republic of Congo also announced confirmed cases of Yellow fever [3]. Yellow fever is a viral hemorrhagic disease due to infected mosquito's bite; it is one of more lethal viral diseases [8-11]. Disease cycle is maintained in nature by circulation of the Aedes genus virus between wild signs and mosquitoes. That makes its eradication difficult and, currently, control and prevention of disease by immunization constitute the public health intervention strategies for populations at risk. With $17 \mathrm{D}$ vaccine of the Rockefeller Foundation, produced in 1936 [12] and introduced into routine immunization programs in years 1965, there was a quasi disappearance of yellow fever in countries where vaccine coverage is high. However, in countries where this immunization encounters difficulties, yellow fever remains always a true public health problem at various degrees [8]. During this last decade, there has been a true resurgence of incidence cases [13]. This resurgence undoubtedly led WHO to consider the case definition revision of yellow fever in October 2010 [14]. During the year 2010, Burkina Faso notified confirmed cases of Yellow fever, including cases coming from villages bordering with Ivory Cost. The goal of this work is to present reference 
yellow fever laboratory 2010 results and stressing transfrontier cases management problems, in order to suggest a multinational mechanism of response to fight against this disease more effectively.

\section{Methods}

Centre MURAZ of Bobo-Dioulasso lodges National Reference laboratory for yellow fever in Burkina Faso. For all the 65 Health Districts of the country, a Blood sample of 5 to $10 \mathrm{ml}$ is carried out from any feverish jaundice case suspecting yellow fever and sent to Centre MURAZ. Transport is done in freeze isotherm boxes at $+4^{\circ} \mathrm{C}$ of temperature. An investigation sheet accompanies each blood sample. At national reference laboratory, one proceeds in specific IgM of yellow fever research by ELISA technique with Center for Diseases Control of Atlanta (United States) kits according to following technique. After antibodies capture by fixation and blocking unsaturated sites by PBS- $0.05 \%$ Tween 20 milk, serums to be tested, beforehand inactivated to $56^{\circ} \mathrm{C}$ during 30 minutes and diluted to $1 / 100$ in PBS- $0.05 \%$ Tween 20 milk, are deposited. After one hour incubation at $37^{\circ} \mathrm{C}$ in wet chamber, yellow fever virus antigen and control negative antigen are diluted to $1 / 40$ PBS- $0.05 \%$ Tween 20 milk and are distributed in parallel in their respective cups. Monoclonal detecting antibody (MAb) specific of glycoproteines of surface of viral envelope which is used is the 6B6C-1 peroxidase of raifort (6B6C-1-HRP) is diluted to $1 / 6000$ in PBS- $0.05 \%$ Tween 20 milk; it is revealed by the substrate ortho-phenylene-diamine (OPD). After reaction stopped by $\mathrm{H}_{2} \mathrm{SO}_{4} 4 \mathrm{~N}$ and plate reading with spectrophotometer at $405-410 \mathrm{~nm}$, positive results are those for which difference in optical density (OD) between positive cups antigen and negative antigen is higher than 0.2. When a sample gives a positive ELISA result, an aliquot sample is sent to Pasteur Institute of Dakar for confirmation. Pasteur Institute of Dakar tests again samples sent by ELISA and sero neutralization for yellow fever and for others arboviroses, in particular Chikungunya, Dengue, Crimean Congo hemorrhagic fever, West Nile, and Rift valley fever. The confirmation is made by Pasteur Institute of Dakar when the sample remains positive by ELISA and by sero neutralization test, and negative for the other arboviroses. Rarely, the sample is tested by RT-PCR to identify yellow fever RNA virus, when sample is carried out in the ten days after the beginning of disease symptoms. Results of Dakar are transmitted to Centre MURAZ by electronic message and fax. A copy of all results is sent to regional health directions from which cases come, with Health Ministry central structures (DLM, PEV) and with WHO country office. Investigation sheet supplemented by laboratory results are seized and analyzed on EPI Info 2000.

\section{Results}

From January to December 2010, National Reference laboratory for yellow fever has received 970 samples coming from suspected cases of yellow fever in the whole country (Figure 1). Among which eleven appeared positive in specific IgM against yellow fever with ELISA method, which represent $1.13 \%$ of suspected cases (Figure 2). Aliquot of these positive samples were sent to Pasteur Institute of Dakar (PID) for confirmation by the combination of ELISA and sero neutralization tests. Eight cases were confirmed as yellow fever by the PID. Among the eight confirmed cases, four were notified by Sindou Health District (Cascades Heath Region) of which three were residents of villages bordering with Ivory Cost, precisely from Ferkessedougou. The tree others confirmed cases were resident of Mangodara Health District, located in the same Health Region; and the eighth case came from Nongr-Massom Health District of Center Health Region (Sector 25 of Ouagadougou). Socio demographic characteristics of positive cases are summarized in Table 1. Out of the eight confirmed positive cases, six were male gender. Six out of the eight cases were not vaccinated. For the two remaining, one had an unknown vaccine status and the other did not have any information on clinical sheet. The three samples not confirmed by Pasteur Institute of Dakar were declared doubtful, because these three cases gave positive results with CDC Kits, the same one used by Centre MURAZ, and negative results with the combination of ELISA and sero neutralization tests of Pasteur Institute. Two of these doubtful cases came from sector 21 of Bobo-Dioulasso in Do Health District. The first case was a 2-years girl having received yellow fever vaccine ap-

Table 1. Socio demographic characteristics of yellow fever confirmed cases, 2010.

\begin{tabular}{|c|c|c|c|c|}
\hline $\begin{array}{c}\text { (Health Regions) } \\
\text { Notification } \\
\text { Districts } \\
\end{array}$ & Age & Gender & $\begin{array}{c}\text { Vaccinal } \\
\text { Status }\end{array}$ & Residence Areas \\
\hline \multirow{4}{*}{$\begin{array}{c}\text { (Cascades) } \\
\text { Sindou }\end{array}$} & 6 years & $\mathrm{M}^{*}$ & $\begin{array}{c}\text { Not } \\
\text { Vaccinated }\end{array}$ & Ferkéssédougou \\
\hline & 6 years & M & $\begin{array}{c}\text { Not } \\
\text { Vaccinated }\end{array}$ & Ferkéssédougou \\
\hline & 2 years & $\mathrm{F}^{* *}$ & $\begin{array}{c}\text { Not } \\
\text { Vaccinated }\end{array}$ & Ferkéssédougou \\
\hline & 5 years & M & $\begin{array}{c}\text { Not } \\
\text { Vaccinated }\end{array}$ & Salenténé (Sindou) \\
\hline \multirow{3}{*}{$\begin{array}{l}\text { Mangodara } \\
\text { (Centre) }\end{array}$} & 5 years & M & $\begin{array}{c}\text { Not } \\
\text { Vaccinated }\end{array}$ & Mangodara \\
\hline & 2 years & $\mathrm{F}$ & $\begin{array}{c}\text { Not } \\
\text { Vaccinated }\end{array}$ & Mangodara \\
\hline & 4 years & M & Unknown & $\begin{array}{l}\text { Linguékoro } \\
\text { (Koflandé) }\end{array}$ \\
\hline Nongr-Massoum & 20 years & M & $\begin{array}{c}\text { Not } \\
\text { Indicated }\end{array}$ & $\begin{array}{c}\text { Sector } 25 \text { of } \\
\text { Ouagadougou }\end{array}$ \\
\hline
\end{tabular}




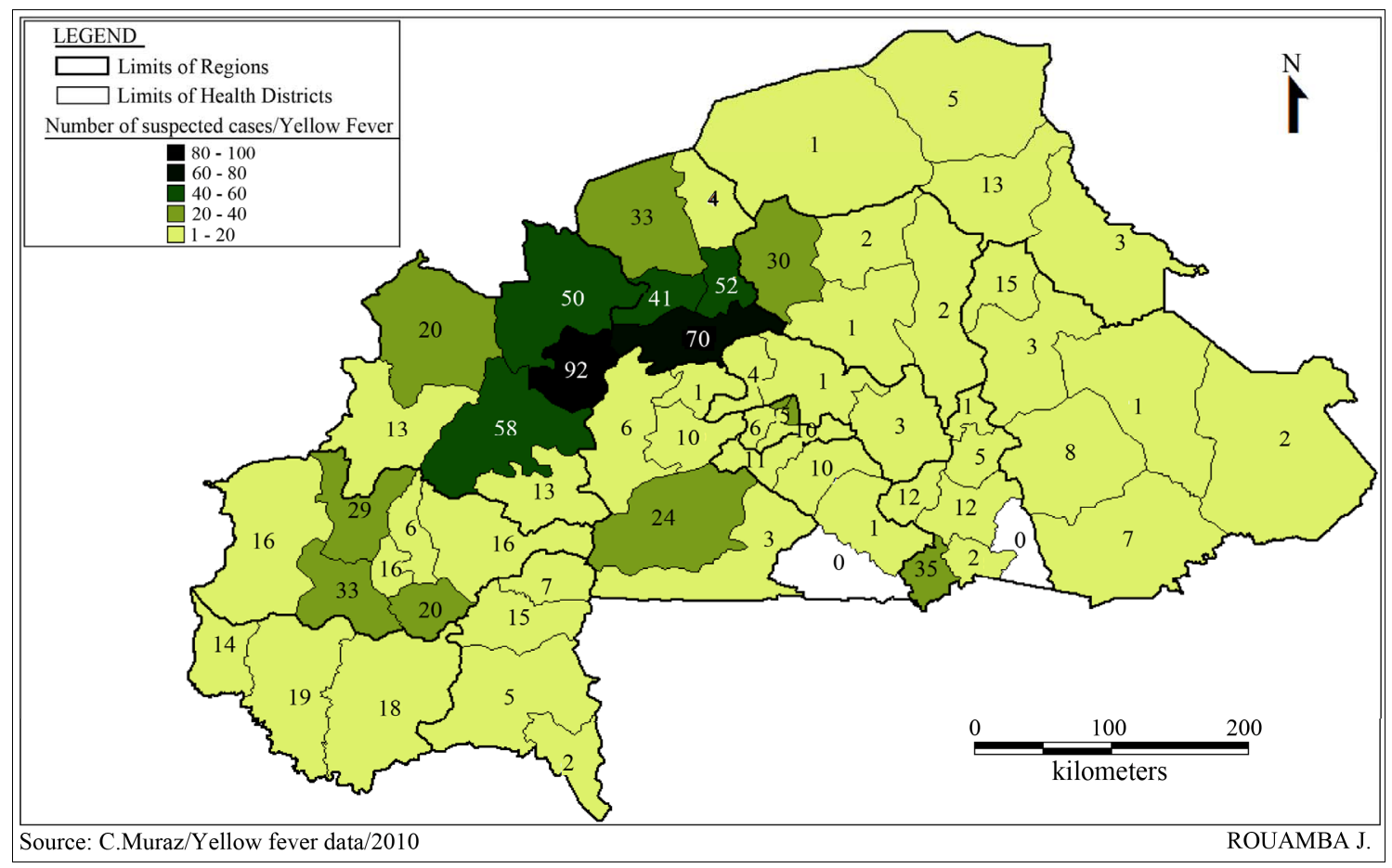

Figure 1. Distribution of suspected case of yellow fever by Health Districts, 2010.

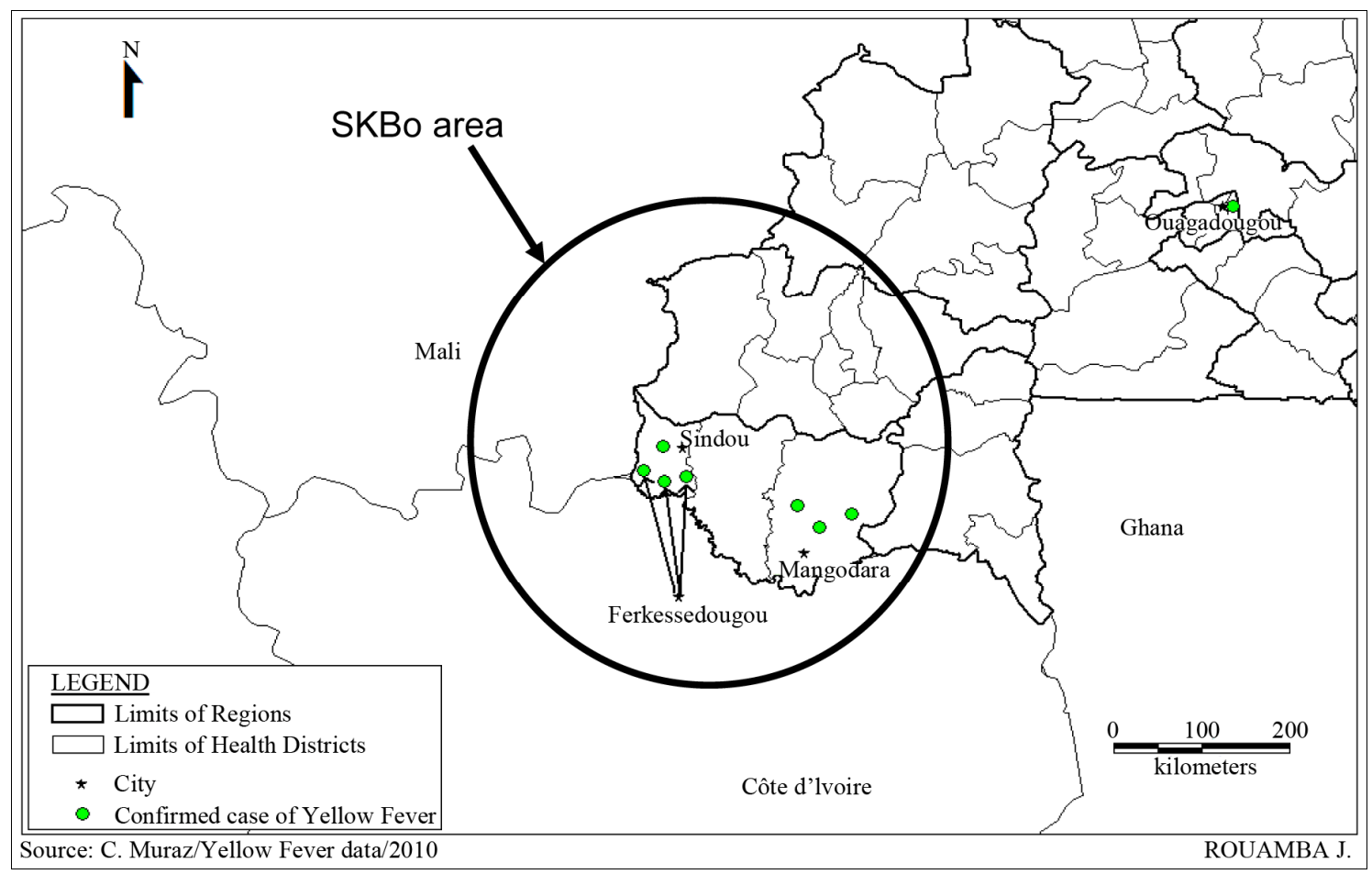

Figure 2. Confirmed cases of yellow fever distribution according to the source, 2010.

proximately 7 months before clinical episode beginning and who died early after blood sampling at medical care unit. The second case was the mother of the latter, 26 years old, whose vaccine status was unknown. Blood sampling has been performed 5 days later within medical care. The third doubtful case was a man aged 44 years and resided at sector 25 of Ouagadougou. Following Pasteur Institute of Dakar request to seek to carry new blood sample from these patients, we tried to find the two cases but the 26-year-old lady was dead one week after 
her release of medical care, and, unfortunately, no information could be retrieved for the men of sector 25 of Ouagadougou.

\section{Discussions}

It is recognized that early detection of yellow fever and a fast response via emergency campaign immunization is essential for an effective fight against outbreak [15]. 17D anti amaril vaccine has existed for several decades [12], $[16,17]$. It is effective and safe and only one dose would be sufficient for a ten-year protection, even more $[18,19]$. Burkina Faso introduced anti amaril vaccine into the Expended Program of Immunization (EPI) since 1987. It is administrated to children at 9 months age at the same time with measles vaccine. It is advised to make recall dose each 10 years. If EPI made enormous progress regarding anti amaril vaccine cover these last years, management of recalls doses is practically not followed in the country, except for people who want to travel out of Burkina. Anti amaril vaccine is obligatory at international level for travelers for endemic area $[8,17,20]$. In Burkina Faso, yellow fever national monitoring organization is mainly dependent on resources allocated by WHO for measles and Acute Flask Paralyses (AFP) monitoring as in the majority of other African countries [21]. The laboratory functions because of regular donations in equipments, consumables and reagents offered by WHO country Office starting from measles and AFP monitoring funds. National reference laboratory transmits results obtained to diseases monitoring office of Health Ministry. Administrative and medical information management on results falls on this office of Health Ministry. The laboratory does not have logistics means enabling it to initiate an investigation immediately when a positive case is detected in a locality, although qualified human resources are available. The lack of logistics means explain why the national laboratory did get information's from the doubtful case of Nongr-masson Transfrontier cases do not profit from particular intervention on behalf of medical authorities of Burkina Faso. In addition, they are ignored by medical responsible of their residence place, whereas populations of these areas live same socio-economic and medical realities and are unaware of frontiers just like diseases. The doubtful results could be explained by the fact that these samples gave limited OD other the cutoff point which is 0.2 at the national reference laboratory. In an others hand, these patients could be at the beginning of the production of specific IgM antibodies against yellow fever when blood samples were carried out. The combination of Elisa test and sero neutralization test at Pasteur Institute were more specific in the detection of yellow fever. Around doubtful cases of Bobo-Dioulasso, revival for a second Blood sampling from patients obviously missed coordination and means to lead a true multi-disciplinary investigation on epidemiologic, virological and entomological plan. Confirmed cases of 2010 come mainly from Western area of Burkina recognized as an area of strong yellow fever endemicity of where cases are regularly described $[5,22]$. This area is frontier with Ivory Cost in its Northern part where cases of yellow fever are often described $[23,24]$; and also with the West of Mali (Sikasso) where one has relatively little information. Most recent literature data show an epidemic occurrence in 1987 in Mali, Kati Area [1,2], then other WHO data revels that Mali announced 53 suspected yellow fever cases of which 23 died in November 2005 on Bafoulabe District level, Kayes Region [25]. This area forms a Sub regional triad favorable in climatic, faunal plan and in vegetable cover plan for circulation of amaril virus. This area known as SKBo space, initials to indicate Sikasso-Korhogo-Bobo, was in line of sight of CEDEAO for concerted medical actions [26]. WHO Data show that Ivory Cost notified 2 yellow fever cases in 2008; 3 cases in 2009 [3] and 12 cases were confirmed in January 2011 [27]. Undoubtedly that confirmed cases identified in Burkina, but resident in North Ivory Cost were not taken into account in view to make profit source areas of these cases of riposte actions implemented by Ivory Cost. In addition, the authorities of Burkina cannot either unilaterally intervene in these areas in riposte event. There is certainly a loss of earnings in this direction by installation of formal framework dialogue and mechanism of information diffusion between medical authorities of these two countries. Meetings of dialogues in SKBo space were already initiated [28]. It would be judicious to start again or reinforce this dialogue framework under West African Health Organization (WAHO) by integrating questions about yellow fever resurgences management. As regards need for concerted management yellow fever situations, according to Cordellier in 1991 [1], after an deepened analysis on yellow fever epidemiology concluded: "what one currently knows shows, obviously, that last difficulties could be overcome only thanks to multinational collaborations. Viral circulations are unaware of frontiers”.

\section{Conclusion}

Yellow fever circulates again in West Africa, more frequently than in previous decades. In addition, for reinforcement of monitoring activities and of National Reference laboratories capacities inside countries, it is necessary more than ever, to find Sub regional concerted management mechanisms and response for a durable control of yellow fever situation in West Africa. WAHO which is the "Health" agency of ECOWAS (Economic Community Of West African States) and which regis- 
tered Sub regional research coordination as one of its strategic plan axes, could well facilitate implementation of these mechanisms and dialogue frameworks with the support of all partners.

\section{REFERENCES}

[1] R. Cordellier, "l’Épidémiologie de la Fièvre Jaune en Afrique de L'Ouest," Bulletin of the World Health Organization, Vol. 69, No. 1, 1991, pp. 73-84.

[2] A. Roisin, "la Fièvre Jaune, une Maladie Toujours d'Actualité en Afrique,” Cahier Santé, Vol. 4, No. 3, 1994, pp. 201202.

[3] WHO, "Yellow Fever in Africa and Central and South America, 2008-2009," The Weekly Epidemiological Record, Vol. 86, No. 4, 2011, pp. 25-36.

[4] H. Attoh-Touré, N. S. Dagnan and J. Tagliante-Saracino, "Résurgence des Épidémies de Fièvre Jaune en Côte d’ivoire," Bulletin de la Société de Pathologie Exotique, Vol. 103, No. 5, 2010, pp. 323-326. doi:10.1007/s13149-010-0047-y

[5] S. Yaro, A. Zango, J. Rouamba, A. Diabaté, et al., "Situation Épidémiolgique de la Fièvre Jaune au Burkina Faso, 2003-2008," Bulletin de la Société de Pathologie Exotiqu, Vol. 103, No. 1, 2010, pp. 44-47.

[6] WHO, "Yellow Fever, Senegal," The Weekly Epidemiological Record, Vol. 85, No. 41, 2010, pp. 401-412.

[7] WHO, "Yellow Fever, Uganda," The Weekly Epidemiological Record, Vol. 86, No. 5, 2011, pp. 37-44.

[8] T. P. Monath and M. S. Cetron, "Prevention of Yellow Fever in Persons Traveling to the Tropics," Clinical Infectious Diseases, Vol. 34, No. 10, 2002, pp. 1369-1378. doi:10.1086/340104

[9] A. A. Sall, O. Faye, M. Diallo, C. Firth, et al., "Yellow Fever Virus Exhibits Slower Evolutionary Dynamic than Dengue Virus,” Journal of Virology, Vol. 84, No. 2, 2010, pp. 765-772. doi:10.1128/JVI.01738-09

[10] P. F. Vasconcelos, "Yellow Fever in Brazil: Thoughts and Hypotheses on the Emergence in Previously Free Areas," Revista de Saúde Pública, Vol. 44, No. 6, 2010, pp. 11441149. doi:10.1590/S0034-89102010005000046

[11] J. da C. Cardoso, M. A. De Ameida, E. Dos Santos, D. F. Da Fonseca, et al., "Yellow Fever Virus in Haemagogus leucocelaenus and Aedes serratus Mosquitoes, Southern Brazil, 2008,” Emerging Infectious Diseases, Vol. 16, No. 12, 2010, pp. 1918-1924. doi:10.3201/eid1612.100608

[12] M. Theiler and H. H. Smith, "The Use of Yellow Fever Virus Modified by in Vitro Cultivation for Human Immunization,” The Journal of Experimental Medicine, Vol. 65, No. 6, 1937, pp. 787-800. doi:10.1084/jem.65.6.787

[13] S. E. Robertson, B. P. Hull, O. Tomori, et al., "Yellow Fever. A Decade of Reemergence,” The Journal of the American Medical Association, Vol. 276, No. 14, 1996, pp. 1157-
1159. doi:10.1001/jama.1996.03540140045025

[14] WHO, "Yellow Fever Surveillance and Outbreak Response: Revision of Case Definitions, October 2010,” The Weekly Epidemiological Record, Vol. 85, No. 47, 2010, pp. 465-472.

[15] WHO, "Yellow Fever Fact Sheet," The Weekly Epidemiological Record, Vol. 85, No. 5, 2010, pp. 29-36.

[16] J. G. Frierson, “The Yellow Fever Vaccine: A History," Yale Journal of Biology and Medicine, Vol. 83, No. 2, 2010, pp. 77-85.

[17] A. A. Neilson and C. A. Mayer, "Yellow Fever. Prevention in Travelers," Australian Family Physician, Vol. 39, No. 8, 2010, pp. 570-573.

[18] J. D. Poland, C. H. Calisher, T. P. Monath, et al., "Persistence of Neutralizing Antibody 30 - 35 Years after Immunization with 17D Yellow Fever Vaccine,” Bulletin of the World Health Organization, Vol. 59, No. 6, 1981, pp. 895-900.

[19] WHO, "International Travel and Health,” WHO, Geneva, 2007.

[20] WHO, "International Travel and Health,” WHO, Geneva, 2009.

[21] A. A. Fatiregun, A. O. Sangowawa and O. A. Abubacar, "Outcome of Training on Yellow Fever Surveillance in a South-Western State, Nigeria: implication for Improved Field Implementation,” Nigerian Journal of Clinical Practice, Vol. 3, No. 4, 2010, pp. 449-452.

[22] H. Barrenes, T. Baldet, A. M. Casel, C. Kabire, et al., "Riposte Vaccinale et Persistance d'un Risqué Épidémique de Fièvre Jaune Dans la Région de Gaoua au Sudouest du Burkina Faso: Intérêt d'une Équipe Pluridisciplinaire,” Sante, Vol. 12, No. 3, 2002, pp. 323-329.

[23] C. Akoua-Koffi, S. Diarrassouba, V. B. Bénié, J. M. Ngbichi, et al., "Investigation Autour d'un cas Mortel de Fièvre Jaune en Côte d'Ivoire en 1999,” Bulletin de la Société de Pathologie Exotique, Vol. 94, No. 3, 2001, pp. 227-230.

[24] Y. L. Konan, A. B. Kone, K. D. Ekra, J. M. Doannio and K. P. Odehouri, "Entomological Investigation Following the Re-Emergence of Yellow Fever in 2008 in Abidjan Area (Côte d'Ivoire)," Parasite, Vol. 16, No. 2, 2009, pp. 149-152. doi:10.1051/parasite/2009162149

[25] WHO, "Yellow Fever Mali-Update," The Weekly Epidemiological Record, Vol. 80, No. 48, 2005, pp. 417-424.

[26] Rapport final SKBo, "Etude de Faisabilité Pour Une Action Pilote des Zones Frontalières de Sikasso-KorhogoBobo-Dioulasso,” Août, 2005, 40 Pages.

[27] WHO, "Yellow Fever, Côte d'Ivoire," The Weekly Epidemiological Record, Vol. 86, No. 6, 2011, pp. 45-52.

[28] Document SKBo, “Atelier de Lancement d’une Opération Pilote de Coopération Transfrontalière,” Tenu à Sikasso (Mali) les 27, 28 et 29 Septembre 2005, Octobre 2005, 12 Pages. 